Australian hospitals. J. Loughman and A. B. Watson ${ }^{5}$ offer a safety code which, though apparently complicated, reduces to a few simple rules for users of equipment. A survey by P. S. Monks ${ }^{6}$ also includes much sound practical advice.

In general the problem calls for close collaboration between clinicians and engineers, critical review of hospital electrical installations, and-most of all-a vigorous educational programme to instruct doctors, nurses, and technicians in the hazards which accompany the benefits of modern electronic technology.

\footnotetext{
${ }^{1}$ McIntosh, H. D., Starmer, F., and Whalen, R. E., American Heart

Fournal, 1966, 72, 419.
${ }^{2}$ Electrical Hazards in Hospitals, ed. Walter, C. W., p. 66. National Research Council, Washington, U.S.A., 1970

3 Health Devices, 1971, 1, 4.

Health Devices, 1971, 1, 4.

' Bruner, J. M. R., Anesthesiology, 1967, 28, 396. 349.

- Monks, P. S., Anaesthesia, 1971, 26, 264.
}

\section{Mixture as Before}

In 1969 the large isolated mental hospitals, as Sir Keith Joseph called them in the House of Commons last week, still treated $77 \%$ of admissions for psychiatric care. ${ }^{1}$ Psychiatric units in general hospitals treated $17 \%$ and the teaching hospitals 7\%. The total figures for England and Wales conceal wide regional differences. In the Manchester region, for example, $44 \%$ of admissions went into units in general bospitals; in East Anglia none.

This snail's pace of change is surprising, because the development of comprehensive services for the mentally ill outside psychiatric hospitals and of "community care" have been official policy since the Mental Health Act of 1959, and the policy has been reiterated in papers and pronouncements many times since then. The policy outlined last week in a report ${ }^{2}$ from the Department of Health not only consolidates the advice offered previously-the development of inpatient units in general hospitals, of day hospitals, of outpatient services, and the local authority facilities that are essential if "community care" is to mean anything-but it also goes farther. "The objective should be to establish a department for the mentally ill in each district general hospital or group of hospitals providing a district service with the ultimate aim of replacing the large mental hospitals," says the report, and detailed advice is given about the transition period. The emphasis is on teamwork and on close working arrangements between hospital staff teams, each looking after the needs of a population of 60,000 and working in all the units concerned including (transitionally) a division of a psychiatric hospital, and local general practitioners, local authority social workers, and voluntary workers. The proposals are certainly in the realm of the possible and indeed are in train in some areas.

Whether the aims and detailed changes are all desirable is another matter, though they certainly meet with the approval of the Hospital Advisory Service. ${ }^{3}$ Few would dispute that patients needing short and medium term care should be treated near their homes, nor that the later stages of rehabilitation of long-term patients should take place in the community too-if and when enough and varied hostels, day centres, and workshops are built and in operation. Where the fairly small number of chronic schizophrenic patients with or without personality disorders, whose appearance, eccentricity, and wayward-if not actually criminal-behaviour, are best looked after is another matter; and the same question can be asked about those who cannot, will not, or at least do not fall in with the tidy arrangements for their care and "rehabilitation." Perhaps some psychiatrist rejecting his new role as leader of a "multi-disciplinary therapeutic team" 2 might ask these patients what type of care they would prefer and defend his profession's reputation for tolerance and kindliness against the new orthodoxy. $\mathrm{He}$ might also ask the patient's relatives, if there are any.

If this document encourages anyone to discharge patients prematurely to the care of social service facilities which are overloaded and creaking or which exist only on paper it will do a disservice to everyone. Its content may certainly be welcomed as the pattern for the future. But the timing is singularly inept. The local authority social service departments are still reeling from the effects of the Local Authority Social Services Act of 1970 (Seebohm). Whatever the longterm benefits of this measure may be it is unhappily true that in many areas the mental health social service has suffered bad damage and that working relationships between hospital and town hall, built up laboriously over many years, are in jeopardy if not destroyed. It will need more than that old standby 4 "multi-disciplinary training seminars" to restore efficient and trusting relations. The provision of sufficient local authority facilities in all their necessary variety, if they are to replace those of psychiatric hospitals, will also need a great deal of money.

The new memorandum is silent on two topics of crucial importance. Where is psychiatric nurse training to be provided? The excellent quality of training provided in our large psychiatric hospitals is going to be hard to replace and it is good by virtue of their size. Will general hospital units be able to provide it? Neither does the memorandum deal with "services for elderly patients whose mental illness symptoms are the result of ageing or physical disease or both. Provision for these services is under review." The number of patients aged 65 or more in psychiatric hospitals for over two years has remained ${ }^{1}$ stationary between 1954 and 1969 at about 36,000 . If the beds are there already are they to be replaced in the community, or elsewhere, at a cost of how many scores of millions of pounds? Till then at least, and perhaps for longer "isolated, majestic, imperious," in Mr. Enoch Powell's phrase, the mental hospitals will continue to rise "unmistakable and daunting out of the countryside."

1 Department of Health and Social Security, Statistical Report Series No. 12. Psvchiatric Hospitals and Units in England and Wales. London. H.M.S.O. 1971, Table 9.

2 Denartment of Health and Social Security, Hospital Services for the Mentallv Ill. London. H.M.S.O.. 1971.

3 National Health Service Hospital Advisory Service, Annual R॰port for 1969-1970. London, H.M.S.O., 1971, paragraph 5758.

+ Department of Health and Social Security, Circular LASSL 33/71. 